\title{
A INTERPRETAÇÃO NOS ESTUDOS DA CANÇÃO BRASILEIRA
}

\author{
THE INTERPRETATION ON BRAZILIAN'S SONG STUDIES
}

\author{
Beatriz Schmidt Campos ${ }^{1}$
}

\begin{abstract}
RESUMO: Considerando a importância dos estudos da canção para o ensino da língua portuguesa e para pesquisas sobre questões socioculturais brasileiras, abordaremos a interpretação como ampliação à compreensão da letra e da melodia. Para tanto, apresentaremos um estudo sobre o conceito de interpretação, advindo das reflexões de Antonio Candido (1996) nas análises de poesia, do pensamento de Umberto Eco $(2005,2010)$ sobre interpretação, e Paul Zumthor (1997), no âmbito da interpretação vocal, além de uma reflexão sobre a relevância de seus estudos para maior entendimento da canção e seus contextos. Sob esse aspecto, analisaremos Flores horizontais (2000) de Oswald de Andrade e Zé Miguel Wisnik, gravada por Elza Soares no disco Do cóccix até o pescoço (2002).
\end{abstract}

Palavras-chave: Estudos da Canção; Interpretação; Elza Soares.

ABSTRACT: Considering the relevance of the studies of song for the Portuguese language studies e for the research about Brazilian sociocultural issues, we will approach the interpretation as an enlargement for the understanding of the lyrics and melody. Therefore, we will present a study about the concept of interpretation, derived from Antonio Candido's (1996) reflections about poetry analysis, the thoughts of Umberto Eco (2005, 2010) about interpretation and Paul Zumthor (1997) on vocal interpretation issues. Beyond that, we will present a reflection about the relevance of the studies of interpretation for a greater understanding of the songs and their contexts. About this, we will analyze Flores horizontais (2000) by Oswald de Andrade and Zé Miguel Wisnik, recorded by Elza Soares on her CD Do cóccix até o pescoço (2002).

Keywords: Song Studies; Interpretation; Elza Soares.

\section{INTRODUÇÃO}

Nas últimas décadas, o estudo da letra da canção brasileira tem contribuído para a compreensão gramatical e textual do ensino da língua portuguesa, e tem sido suporte ao

\footnotetext{
${ }^{1}$ Possui Graduação em Música pela Universidade de Brasília (1999) e Mestrado em Literatura pela mesma instituição (2017), na linha de Literatura e outras Artes. Tem experiência na área de Artes, com ênfase em Literatura e Música, atuando principalmente nos seguintes temas: Relações entre Literatura e Música e Estudos da Canção. E-mail: bscampos@yahoo.com.br
} 
entendimento de questões socioculturais e políticas do Brasil, sobretudo no ensino médio e nas universidades. Embora não se negue a relevância dos referidos estudos para a compreensão da história do país e das questões sociais que eles abarcam, Robson Coelho Tinoco e Marília de Alexandria (2010) propõem a relevância do estudo da melodia e da letra para maior compreensão da canção e das relações entre música e literatura e seus aspectos culturais. Para os autores:

Sob o sentido binário estrutura x conteúdo se notam sinais de aproximação entre música e poema por meio da observação da teoria musical e de elementos textuais de literariedade (Tinoco; Alexandria, 2010, p. 210). [...] A referencial percepção melopoética passa a ser uma ferramenta metodológica que precisa ser devidamente utilizada a partir de leituras pertinentes, e com apurado senso crítico, tanto da área de poética quanto à de música (TINOCO; ALEXANDRIA, 2010, p. 210).

Seguindo essa visão, ressalta-se a importância dos estudos da letra e da melodia para um entendimento mais aprofundado de uma canção, e pensamos que uma terceira via de análise seria a observação de suas interpretações que, por meio de suas variações, enfatizam aspectos vocais e musicais, que poderão permitir a ressignificação de uma canção. Nesse sentido, os autores afirmam que:

O leitor de uma obra musical pode representar vários papeis de recepção/ação, desde o de simples ao mais erudito ouvinte, até ao de várias espécies de intérprete: um instrumentista popular ou clássico, o cantor de um lied, o regente de uma banda, coral ou orquestra sinfônica. A performance desses papeis tem seu início em uma leitura ou interpretação, ação criadora do ouvinte intérprete, ambos executantes da partitura-texto (TINOCO; ALEXANDRIA, 2010, p. 211).

Sob esse olhar, apresentamos algumas indagações sobre as quais pretendemos refletir e responder ao longo deste texto: o que é a interpretação do leitor, a interpretação do cantor, qual a diferença entre interpretação e performance e, ainda, o que é a interpretação do professor e do crítico literário ou do musicólogo? O que vem a ser um intérprete na música e um intérprete na literatura? Sabemos que, de todo modo, são conceitos referentes à hermenêutica, e que tudo isso é interpretação, porém, o modo como é usado e onde é usado diferencia-se.

Portanto, pretendemos aqui, como continuidade e aprofundamento dos estudos da canção, abordar o conceito de interpretação na literatura e na música, suas aproximações e seus distanciamentos, partindo da afirmação de Antonio Candido (1996) no ensino de análises de poesia. Segundo o Professor: 
Todo estudo real da poesia pressupõe a interpretação que decorre dela, que pode inclusive ser feita diretamente, sem recurso ao comentário, que forma a maior parte da análise. A análise como comentário é um preâmbulo e para $\mathrm{o}$ professor de literatura e de língua se torna indispensável (Candido, 2004, p. 22).

Nessa via, Candido afirma a importância da análise da poesia (suas estruturas, seus fundamentos, e etc.) que, segundo o autor, deverá ocorrer seguida de uma interpretação. Em seu livro, O estudo analítico do poema (2004), o professor apresenta visões de teóricos como Emil Staiger, que afirmam "que a poesia só pode ser estudada a partir de sua natureza íntima, [...] e que o comentário além de desnecessário talvez seja até prejudicial" (CANDIDO, 2004, p. 23). Visões como essas destacam a relevância dos estudos da interpretação da poesia em detrimento da análise. Embora Candido apresente em seu livro as reflexões acima, sua prioridade é apresentar elementos de análise. Uma análise mais sistemática e estrutural e, desse modo, o professor ensina por meio de exemplos a análise do poema por meio dos estudos de sua sonoridade, ritmo, metro, verso e, ainda, figuras, imagens, temas, alegorias e símbolo e princípios estruturais.

Por meio de suas propostas expostas no livro supracitado, no qual o autor apresenta os primeiros quatro itens de análise: sonoridade, ritmo, metro e verso, podemos perceber que há um paralelo ao estudo da canção quanto à sua análise estrutural. Na canção, a poesia, em fusão com a melodia, apresenta uma sonoridade, ou sonoridades, própria (dada pelos instrumentos, e principalmente pela voz), a canção possui um ritmo que se diferencia do ritmo da poesia em sua leitura e as acentuações da melodia muitas vezes deslocam o acento da palavra em si, o que também poderá deslocar a metrificação. E, por último, a frase melódica diferencia-se da maneira como o verso é lido ou declamado por meio das alturas das notas e fins de frases (agudo e grave). Portanto, faz-se relevante refletir sobre a diferença formal que existe nos estudos da letra da música e da canção (letra e música).

Por sua vez, as figuras, as imagens, os temas, as alegorias e o símbolo, são elementos que estão compreendidos na letra da canção. A melodia poderá ou não enfatizá-las, porém, o tema em si não sofre alterações.

Partindo dessas observações, percebemos que esse "manual" de Candido, livro que foi concebido a partir de uma disciplina ministrada pelo professor para o curso de Letras na Universidade de São Paulo, apresentou-nos muito mais do que observações sobre a importância da interpretação da poesia. Constatamos que seu livro é uma fonte de estudos que pode ser 
utilizado como referência não só aos estudos da poesia como também da canção, desde que se faça os devidos paralelismos.

Seguindo essas reflexões, indagamos: como se dá a interpretação (analítica) de uma poesia e de uma canção? Onde elas se aproximam e se distanciam?

Embora o objetivo de Candido nesse curso específico não fosse ensinar os elementos que produzissem interpretações analíticas de poesia, o Professor enfatiza algumas vezes em seu livro a relevância da interpretação, e afirma que a análise da poesia poderá ser suprimida, porém a interpretação não, para o autor: "Fique claro que não há comentário válido sem interpretação; e que pode haver interpretação válida sem comentário" (Candido, 2004, p. 25). Sob esse aspecto, há uma valorização da interpretação sobre a análise ou comentário.

Para um maior aprofundamento do conceito de interpretação em geral (que vale para os estudos de literatura, de música e de outras artes), buscamos nos aprofundar na visão de Umberto Eco. Para o teórico: "Interpretar um texto significa explicar por que estas palavras podem fazer várias coisas (e não outras) através do modo pelo qual são interpretadas" (ECO, 2005, p. 28)

Nessa via, interpretar é explicar "as palavras" de variadas maneiras, porém, exclui-se outras explicações que não são plausíveis. Para o autor: “a interpretação é indefinida. A tentativa de procurar um significado final intangível leva a aceitação de uma interminável oscilação ou deslocamento de significado" (ECO, 2005, p. 37). E ainda: "Um texto é um universo aberto em que o intérprete pode descobrir infinitas interconexões" (ECO, 2005, p. 45). Entretanto, Eco (2010) reflete também que existe uma intenção profunda do texto, um sentido primeiro, literal, que mantém o sentido de um texto.

A partir das afirmações de Eco, pretendemos fazer uma reflexão da canção como texto. Ou seja, adequar as citações aqui realizadas aos estudos da interpretação da canção como texto poético-melódico e interpretações variáveis. Sob essa perspectiva, Claus Clüver (2006) afirma que,

[...] uma obra de arte é entendida como uma estrutura sígnica - geralmente complexa -, o que faz com que tais objetos sejam denominados "textos" independente do sistema sígnico a que pertençam. Portanto um balé, um soneto, um desenho, uma sonata, um filme e uma catedral, todos figuram como textos que se "lêem" (CLÜVER, 2006, p. 15).

Desse modo, primeiramente podemos observar que na realização da análise de uma canção há uma interpretação que se realiza semelhantemente à análise de uma poesia: Realiza- 
se a análise estrutural do texto-musical levando em conta a fusão da melodia e a da poesia, e concomitante ou posteriormente, realiza-se uma leitura interpretativa da canção, que geralmente se relaciona a aspectos históricos e contextos sociais de uma sociedade, ou ainda a questões filosóficas, identitárias e etc., que é realizada pelo crítico literário-musical e, algumas vezes, por um professor ou ainda, por um musicólogo.

$\mathrm{Na}$ análise da canção, como abordado anteriormente, faz-se um estudo da melodia e da letra simultaneamente, procurando entender o sentido do texto musical por meio do significado da letra a das alturas das notas e, posteriormente ou concomitantemente, o pesquisador interpreta a melodia poética por meio de estudos sócio-políticos, ou estudos de lírica ou de identidade, etc., presentes no texto-melódico.

Nessa via, propomos ampliar nossas reflexões ao estudo da interpretação, porém sob a ótica do intérprete musical, o músico, o cantor que é o primeiro intérprete de um texto-musical, e o sujeito que materializa uma canção, já que não há canção sem voz. Tinoco e Alexandria (2007) afirmam que os papéis da interpretação têm seu início em uma primeira leitura e interpretação, ação criadora do ouvinte/intérprete, ambos “executantes".

Portanto, o cantor é o primeiro intérprete, é aquele que lê/ouvindo (o texto e a partitura ou a gravação) e de maneira intuitiva ou não, decide como vai cantar a canção. Quais notas/sílabas serão alongadas, enfatizadas, cortadas, cantadas de maneira mais pausada, ou mais prolongada, quais frases serão repetidas, enfatizadas, cantadas com mais dramaticidade ou não, e etc. Esses recursos sonoros advindos de uma interpretação prévia permitem inúmeras interpretações musicais.

Sob esse olhar, podemos ressaltar dois parâmetros de análise e de interpretação musical apresentados pelo músico Leonard Meyer que são:

O parâmetro sintático que inclui a harmonia, a melodia e o ritmo. O parâmetro não sintático que inclui dinâmica (volume das notas ou da frase), densidade (quantidade de sons simultâneos- densidade mais densa, são muitos sons simultâneos, menos densa, são poucos sons simultâneos em uma passagem musical), tessitura (alcance do instrumento ou da voz, do som mais grave ao mais agudo), duração da nota, timbre e pausa (silêncio). (MEYER apud SARATH, 2010, p. 514, tradução nossa).

Desse modo, os parâmetros sintáticos relacionam-se aos estudos analíticos estruturais de uma canção (ritmo, melodia ou frases melódicas e harmonia), e os não sintáticos à estudos interpretativos musicais. Dinâmica, densidade, tessitura, duração da nota, timbre e pausa é o que nos interessa observar no âmbito da interpretação musical. 
Seguindo o pensamento acima, faz-se necessário realizar uma breve distinção entre performance e interpretação. Sobre a performance, refletimos sobre a abordagem de Sylvia Toledo em sua dissertação intitulada Maria Bethânia, Corpo e Voz em Cena: a performance de carcará, onde a autora reflete sobre o conceito segundo a teoria de Paul Zumthor:

Na definição do teórico (Zumthor) a performance refere-se a uma ação complexa na qual uma gama de elementos se inter-relaciona compondo a sua totalidade. Zumthor aponta, destarte, para alguns elementos inerentes a qualquer ato performático, quais sejam, o emissor, o receptor e a mensagem poética a ser transmitida. Por outro lado, pontua estarem implícitos nestes elementos outros fatores que envolvem sempre a transmissão da mensagem, podendo ser estes aspectos de fundo, como o tempo, o meio (ou ambiente) e o contexto no qual ocorre a performance, ou ainda mecanismos utilizados na transmissão, como cenário, figurino, corpo, voz e gesto. (TOLEDO, 2012. p. $44)$.

Nesse sentido, a interpretação musical insere-se como um elemento da performance, pois é mais auditivo que visual. Embora não haja performance sem interpretação, podendo ser cantada, falada, declamada ou atuada.

Sob esse olhar, apresentaremos uma breve reflexão sobre a interpretação como expressão artística, mais especificamente como expressão da canção e da interpretação como "modo de fazer arte" que é o caso específico de uma artista como Elza Soares.

\section{Elza Soares - a artista intérprete}

Intérprete de inúmeras canções gravadas em mais de trinta álbuns, Elza Soares, uma das cantoras mais longevas da Música Popular Brasileira, canta o amor, a dor do amor, a luta contra o racismo e contra a fome. Denuncia a pobreza, a desigualdade social, o machismo, a homofobia, a violência contra a mulher, a misoginia e todos os tipos de preconceito. Dona de uma voz única, potente, rouca e de uma técnica singular, Elza Soares recria, ressignifica as letras e as melodias das canções por meio de uma apropriação da artista aos textos e frases melódicas.

Sob essa perspectiva, propõe-se refletir inicialmente sobre alguns aspectos e momentos que constituem a seleção de canções para a elaboração do repertório de um álbum ou show de uma intérprete: a) Uma canção é composta exclusivamente para a voz de uma determinada intérprete. b). Uma obra é pensada e dedicada a uma cantora posteriormente a sua composição. c) E uma obra é escolhida pelo cantor ou cantora para fazer parte de seu álbum. 
Não podemos esquecer o produtor, que poderá interferir na escolha de repertório, às vezes para completar o número de canções previstas, ou mesmo para complementar uma temática principal escolhida para a elaboração do álbum. Sob esses aspectos, gravar um disco é um processo que se inicia por meio de diálogos e contratos entre a artista, o produtor e a gravadora, que fazem parte de um mercado fonográfico e, sob alguns aspectos, buscam corresponder às exigências desse mercado. Portanto, quanto mais se busca atender ao mercado, menos liberdade de escolhas o artista possui.

A artista em questão veio de origem muito pobre e começou a cantar muito cedo para sobreviver. É conhecida a história da cantora sobre sua primeira apresentação no rádio, quando Elza Soares, com apenas treze anos, compareceu ao programa de Ary Barroso. Segundo o depoimento da cantora2: "Eu fugi de casa pra cantar no programa do Ary Barroso [...] O Ary tinha dito que tinha nascido uma estrela naquele momento". O entrevistador lhe pergunta "o Ary Barroso perguntou de que planeta você vinha, você respondeu que...” Elza respondeu: Que eu vim do planeta fome. Do mesmo planeta que ele".

Desde então, cantar para Elza Soares foi um modo de viver e de superar sua pobreza. E apesar de ter gravado inúmeros long plays e compact discs, a cantora participava de todos os trabalhos para os quais era convidada, porém, sempre que a letra da canção fazia referências a algo que tivesse a ver com sua história de vida, a cantora acentuava esse aspecto em alguma entrevista. Como exemplo, quando a cantora cantou meu guri, de Chico Buarque (1997), no disco Trajetória, a artista declarou 3: "Eu conheço esse guri, ele existe na minha vida. Tive um filho que perdi por causa de fome".

Seguindo o pensamento acima, podemos refletir que um/a intérprete coloca sua voz única e singular para produzir uma ressignificação da canção. Em Cavarero (2011) há uma singularidade na voz, "que, por si só, é capaz de atestar a unicidade de cada ser humano" (CAVARERO, 2011, p. 17). E ainda:

A emissão fônica voltada pelo canto, a voz que pressiona o ar e que faz vibrar a úvula tem justamente uma função reveladora. Melhor ainda, mais que revelar, ela comunica. E comunica precisamente a unicidade verdadeira, vital e perceptível de quem a emite. Não se trata, porém, de uma comunicação fechada no circuito entre a própria voz e o próprio ouvido, mas de um comunicar-se da unicidade que é, ao mesmo tempo, uma relação com outra unicidade. É preciso ao menos um dueto, um chamado e uma resposta: isto é,

\footnotetext{
${ }^{2}$ Entrevista concedida à Revista Bravo em agosto de 2002.

${ }^{3}$ Entrevista disponível na Folha de São Paulo, em 02 set. 1997.
} 
uma recíproca intenção de escuta, já ativa na emissão vocal que revela e comunica cada um ao outro (CAVARERO, 2011, p. 20).

Portanto, qualquer cantor ou cantora, ou até um não cantor ou uma não cantora, é dono ou dona de uma voz única e particular.

Desse modo, resta-nos refletir por que pensar na figura do "intérprete" nos estudos da canção? E aqui nós voltamos ao nosso comentário anterior: Elza recria, ressignifica a canção, valorizando os textos musicais por meio de sua interpretação e performance e principalmente de sua voz. Cavarero (2011) aponta ainda que:

$\mathrm{O}$ aspecto original da vocalidade, enquanto novo objeto de estudo, diz respeito então a uma análise da voz que prescinde do tradicional privilégio - não desmentido pelas pesquisas sobre oralidade e sobre a textualidade - da sua relação com a linguagem. É incorporado assim um amplo e recortado horizonte de abordagens que abre novas vias de interpretação para o fenômeno da voz, possibilitando a intervenção de campos de pesquisa múltiplos e heterogêneos [...] é justamente a voz como voz, nas suas múltiplas manifestações, a orientar uma investigação que recupera, cruza, mas também põe em crise, a especificidade dos vários cânones disciplinares (CAVARERO, 2011, p. 27).

Nessa via, pensar a voz da referida cantora requer abrir horizontes, entender a possibilidade de que poderá haver uma camada mais aprofundada na interpretação de uma canção, e isso ocorre quando uma intérprete apropria-se de um texto musical. Em Zumthor (1997):

O interprete é o indivíduo que se percebe, na performance, a voz e o gesto, pelo ouvido e pela vista. Ele pode ser também compositor de tudo ou parte daquilo que diz ou canta. Se ele não o é, será questionada a relação que o liga ao (s) compositor (es) anterior (es). Acontece que o público adota para o intérprete o mesmo comportamento que adota para o autor: a lembrança e o título de uma canção se prendem ao nome de um de seus cantores que a propagam, a ponto de parecer como coisa sua (ZUMTHOR, 1997, p. 225).

Portanto, há também uma apropriação do intérprete, como se aquela canção fosse sua. Para Ricouer: "o termo apropriar joga com o possessivo e com o verbo que significa 'confessar como seu"' (RICOEUR, 2007, p.117). Nessa via, o intérprete primeiramente exerce um papel de leitor/ouvinte, sua leitura/escuta gera uma interpretação que permite que haja outra leitura, ou seja, outra versão que será apresentada ao público por meio de sua voz e de seus gestos. 
E, aprofundando essa abordagem, acreditamos que a apropriação poderá ocorrer ou não. A apropriação sucede quando por meio da interpretação há realmente um reconhecimento de si naquela letra e melodia. Zumthor reflete que: "o texto poético oral leva necessariamente o ouvinte a se identificar com o mensageiro das palavras sentidas em comum, ou até com as próprias palavras" (ZUMTHOR, 1997, p. 247).

Por meio da apropriação, o intérprete faz sua aquela canção e sua performance poderá causar um efeito de reconhecimento de si também no ouvinte. Para Bachelard:

[...] a imagem chegou às profundidades antes de movimentar a superfície. Isso é verdade, mesmo na simples experiência de leitor. Assim a imagem que a leitura do poema nos oferece faz-se verdadeiramente nossa. Enraíza-se em nós mesmos. Recebemo-la, mas nascemos para a impressão de que poderíamos cria-la, que deveríamos cria-la. A imagem se transforma num ser novo de nossa linguagem, exprime-nos fazendo-nos o que ela exprime, ou seja, é ao mesmo tempo um devir de expressão e um devir de nosso ser. No caso, ela é a expressão criada do ser (BACHELARD, 1978, p. 188).

Desse modo, pode-se refletir que, primeiramente, esse enraizamento ocorre com o intérprete enquanto leitor/ouvinte e posteriormente com o ouvinte. E é possível que essa apropriação, esse reconhecimento, não suceda com o próprio compositor de uma canção, mas sim com seu intérprete.

Sob essa perspectiva, pode-se refletir ainda sobre as inúmeras interpretações de Elza Soares de uma única canção. Ainda que o objetivo desta comunicação seja apoiar-se em uma versão da canção para análise, é relevante perceber que, ao estudar Elza Soares, deve-se apontar suas inúmeras e diferentes interpretações de uma canção, pois por meio delas pode-se observar uma movência de uma canção, que nos remete aos conceitos de variantes e movência de Zumthor. Para o autor as variantes são: “ [...] diferenças de toda espécie e de toda amplitude por onde se manifesta, na ação performática, a movência da obra [...] Nestas ressaltam-se variações autônomas, mas correlativas, do texto, por um lado e da melodia, por outro" (ZUMTHOR, 1997, p. 268269).

Seguindo o pensamento desse autor, há várias interpretações, porém elas não perdem relações com o texto e com a melodia. O pesquisador acrescenta ainda que "As questões que o mundo lhe coloca não cessam por sua vez de se modificar: bem ou mal, a obra modifica suas respostas" (ZUMTHOR, 1997, p. 272). Nesse aspecto, segundo sua teoria, uma obra pode sofrer modificações e adaptações perante inúmeras interpretações e performances, e às vezes essas mudanças podem ser de forma ou de sentido, dependendo do contexto histórico em que está 
inserida. Segundo o autor, "O texto oral pede uma interpretação também movente. A energia que o sustem e compõe suas formas, a cada performance, recupera a experiência vivida e a integra em seu material" (ZUMTHOR, 1997, p. 272).

Desse modo, percebe-se que a medida na qual a cantora emite sua voz rouca em fim de frases ou no meio, quando acrescenta melismas ${ }^{4}$ às sílabas melódicas, de modo a enriquecê-las, ou ainda quando improvisa rítmica ou melodicamente, o sentido primeiro da canção permanece, sem perder aquilo que Umberto Eco (2010) afirma sobre a "intenção (intentio) profunda do texto". O autor acrescenta ainda que "todo discurso sobre a liberdade da interpretação deve começar por uma defesa do sentido literal" (ECO, 2010, p. 9), mesmo com toda a liberdade que os músicos têm. No entanto, há uma movência em seu sentido e em sua forma por meio da ênfase, que é dada a determinadas frases em detrimento de outras. A cada interpretação esses elementos vocais, que aparecem em momentos diferentes da música, portanto, podem-se escutar inúmeras versões que irão ressignificar a canção.

Refletir sobre interpretação na canção, no âmbito de uma cantora como Elza Soares, nos leva a refletir sobre toda a obra e vida da cantora e tudo o que ela significa enquanto mulher, negra, pobre, vinda da favela, crítica da desigualdade social, do preconceito, da marginalidade, da pobreza e da violência. Segundo Zumthor: "A voz modela fisicamente o que ela diz e, mais ainda o que ela canta. Ela reproduz o fato contado, desenrola-o no seu próprio espaço-tempo. A força do discurso (o talento do cantor) funda definitivamente sua realidade" (ZUMTHOR, 1997, p. 285). Portanto, por meio de sua interpretação há uma retificação da realidade do próprio texto e um "tempo" que se torna presente a cada audição de uma canção.

Ao mesmo tempo em que a voz, as letras, as melodias e os arranjos das canções interpretadas pela cantora nos remetem a um tratado do que tem sido sua vida. As canções cantadas por ela parecem abrir as portas para inúmeras possibilidades vocais e os improvisos que ainda estão por vir. Nesse sentido, Zumthor reflete que: "A performance de uma obra poética encontra, assim, a plenitude de seu sentido na relação que a liga àquelas que a precederam e àquelas que a seguirão" (ZUMTHOR, 1997, p. 265). Trata-se de um devir, de transformações de significado e significantes que são geradas a cada canção que a cantora interpretou e que se espera que fará.

Por meio dessas breves análises, podemos refletir ainda que, embora Elza Soares não seja compositora (pelo menos não é uma característica de sua carreira, pois ela compôs

${ }^{4}$ trecho melódico com várias notas para uma mesma sílaba 
pouquíssimas músicas), sua carreira tem sido marcada por cantar letras que expressam suas vivências pessoais. Obra e vida remetem-se mutuamente, não há uma separação. Sua vida, sua música e sua imagem estão totalmente entrelaçadas e relacionam-se entre as canções, voz, improviso, resistência, protesto, denúncia e dor.

\section{Análise de Flores Horizontais}

Sob os aspectos refletidos anteriormente, apresentaremos um estudo interpretativo da canção "flores horizontais". A letra foi adaptada por José Miguel Wisnik do poema de Oswald de Andrade "Oração do Mangue" e extraída do livro O santeiro do Mangue e outros Poemas, publicado apenas em 1991, para compor uma canção para a voz de Elza Soares, que foi gravada no disco Do cóccix até o pescoço, em 2002. Sob esse aspecto, Elilson Gomes do Nascimento relata:

\footnotetext{
"Oração do Mangue" é o último poema contido em "O Santeiro do Mangue". Obra inacabada, o Santeiro é uma miscelânea entre poesia, texto dramático e sátira, sendo escrito por Oswald entre os anos 30 e 50. Considerado por muitos como o texto mais polêmico da carreira oswaldiana, seu lançamento foi adiado e impedido várias vezes, sendo divulgado ao grande público apenas em 1991, depois de "sessenta anos de clandestinidade". Oswald escolhe como cenário da obra o bairro carioca do Mangue, extinta zona de prostituição, para criticar veementemente as instituições religiosas e o moralismo da sociedade burguesa. "Santeiro" é uma referência a um personagem que vende imagens de santos. (NASCIMENTO, 2012, p. 153).
}

Sob essa perspectiva, o compositor extraiu versos do poema original e modificou algumas palavras para adaptar o texto à melodia da canção.

Letra da canção:

Flores Horizontais, flores da vida

flores brancas de papel,

Da vida rubra de bordel, flores da vida afogadas nas janelas do luar carbonizadas de remédios, tapas, pontapés, escuras flores puras, putas, suicidas, sentimentais.

Flores horizontais.

Que rezais?

Com Deus me deito.

Com Deus me levanto. 
A canção é iniciada com uma introdução de piano, e a forma na gravação que analisamos é $\mathrm{AAA}^{5}$. Entre as partes A há um solo curto de piano, e na segunda e na terceira vez a canção é finalizada com uma melodia que remete a uma ladainha "com Deus me deito, com Deus me levanto”. Na canção composta para Elza Soares, uma balada calma e intimista em tom menor, a cantora enfatiza um tom de oração. Sua letra aborda a vida das prostitutas, que ao mesmo tempo em que vivem em situação de violência, são devotas e rezadeiras.

$\mathrm{Na}$ letra há duplos antagônicos (flores brancas/vida rubra de bordel; flores puras e sentimentais/putas e suicidas), e há uma tensão advinda de melodias com notas iguais quando a cantora canta "flores da vida", que sugerem uma fala (como se observa na figura abaixo). Nos versos "Carbonizadas de remédios, tapas, pontapés/ Escuras flores puras, putas, suicidas, sentimentais", a cantora explora sua tessitura, o volume mais intenso e timbre rouco criando uma atmosfera dolorida para enfatizar os paradoxos puras/putas, suicidas/sentimentais (figura 2) - ressalta-se que esse é o ponto clímax da canção. Na sílaba "tais" da palavra "sentimentais" do verso acima, a cantora utiliza um recurso denominado melisma remetendo ao canto gregoriano que empregava esse recurso para alongar algumas sílabas das letras principalmente em fins de frases.

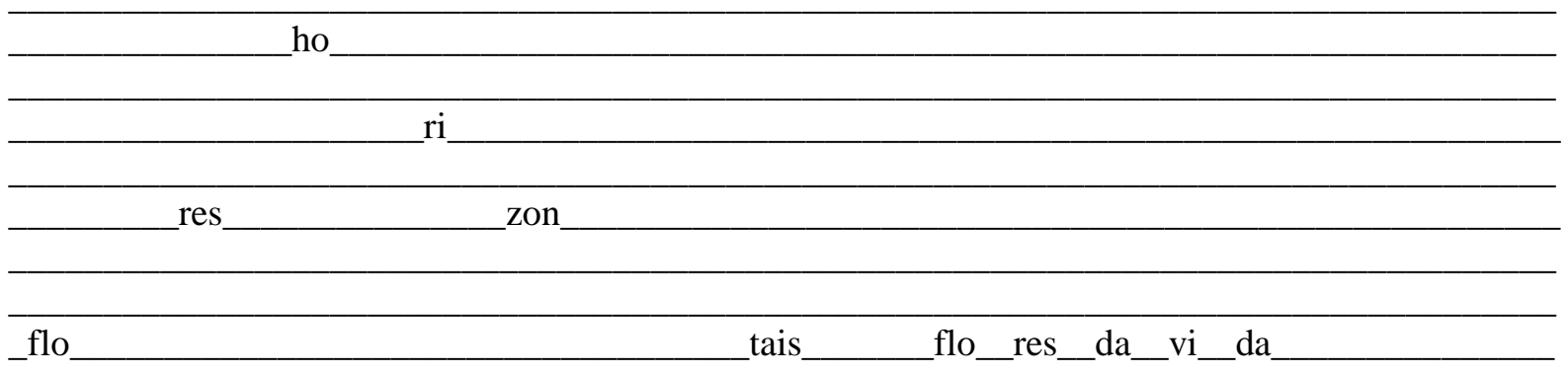

Figura 1. Representação gráfica da melodia. O primeiro espaço (flo) representa a nota "si" e as palavras "flores da vida". A nota mais aguda é "fá\#"

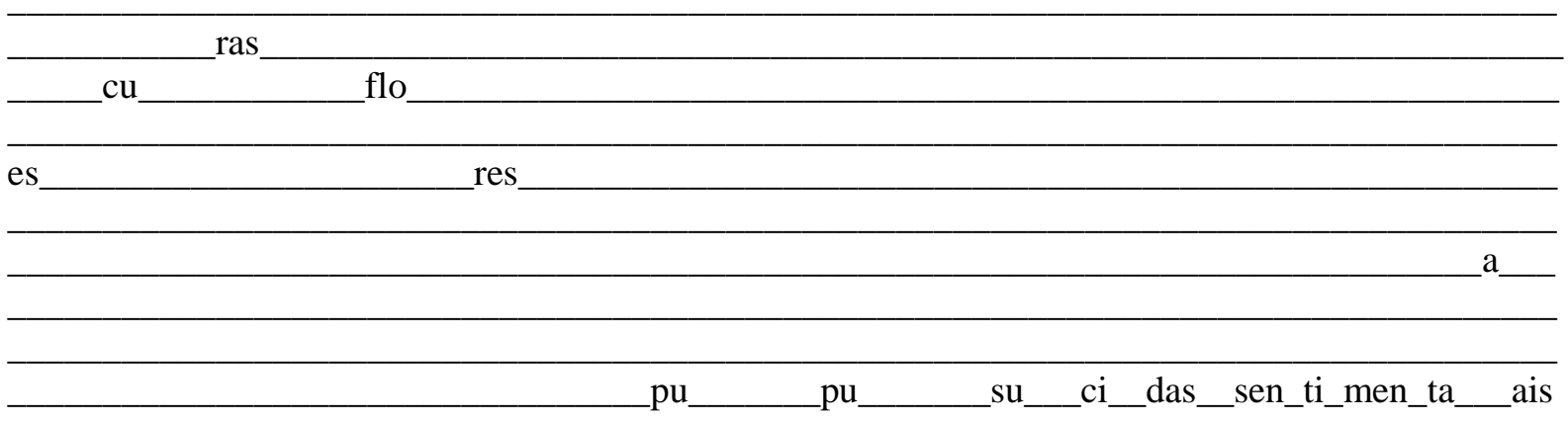

${ }^{5}$ Disponível em: 〈https://www.youtube.com/watch?v=pnloIbqr0nk > Acesso em: 24 abr. 2018. 
ras tas i.

Figura 2. Representação gráfica da melodia. A primeira silaba "es" é a nota "si", porém uma oitava acima, mais agudo.

Ao final, com a voz em volume menos intenso, a cantora canta uma melodia que remete a uma ladainha religiosa:

Que rezais?

Com Deus me deito, com Deus me levanto.

As prostitutas rezam, reforçando o caráter crítico do texto, que, segundo Nascimento:

É nesse ponto que, principalmente, reside a polêmica maior da obra. Oswald promove a união entre o sagrado e o deslustro, [...] O autor ataca, assim, sem rodeios, a religiosidade através de uma escrita "pagã", "ateia", na qual se utiliza até mesmo da parodia de passagens bíblicas e de liturgias católicas. Tal escrita muitas vezes "incorpora" a oralidade das mulheres "incultas" do mangue, no seu modo simples e rude de se expressar (NASCIMENTO, 2012, p. 153).

Sob esse aspecto, percebe-se uma crítica sobre as mulheres que sofrem violências, sobre a hipocrisia da sociedade burguesa que se utiliza dessas mulheres, que não deixam de ter uma fé.

Vale observar que a canção apresenta um caráter imagético advindo dos versos de Mário de Andrade. A imagem vai se apresentando à medida que se lê o poema ou que se escuta a canção. Flores horizontais são as prostitutas deitadas em seu leito, à espera do que a noite vai trazer e, ao mesmo tempo, à espera de Deus.

\section{CONSIDERAÇÕES FINAIS}

Por meio das considerações de Lucia Helena Gayotto (2002), podemos refletir sobre a relevância da interpretação nos estudos da canção e no canto como expressão artística, que por meio da apropriação de um texto musical, pode provocar uma sensação de plenitude que perpassa tempo e espaço, e ainda permite que a audição de uma obra já conhecida se torne uma obra recriada. 
Ouvi muitas vozes em cena. Absorvi, atenta, as substâncias da voz, seus movimentos e diversidades. Fui percebendo que ouvir os recursos vocais isoladamente não dava conta daquilo que atravessou meus sentidos, que era, com certeza, misto desses recursos com outros elementos da interpretação e das sensações que estes me provocavam. Esta escuta permitiu um refinamento no qual a audição reconhece, ao mesmo tempo, as características da voz e sua relação no plano das afecções. Neste estado de escuta o som, o tom, a intenção, as pausas e o subtexto, o volume e a situação, convergem num fluxo necessário de ação da voz. [...] Sinto que nos momentos em que ouço uma emissão vocal de qualidade, sou arrebatada por uma espécie de "esquecimento" de mim, como se fosse envolvida por uma trama invisível, e só depois é que me dou conta de aquela ter sido uma boa interpretação vocal. Esses instantes têm algo de pleno em si. Esta voz faz parte do personagem interpretado, acolhe meus sentidos, me abre para devires em cena... Uma voz em movimento que não é igual ao que foi ontem; está presente há pouco, agora, e cria o novo a cada minuto [...] (Gayotto, 2002, p. 19).

Para finalizar, consideramos relevante o estudo da interpretação como complemento aos estudos da canção. Vale destacar que a letra é o componente mais importante quando se trata de compreender um texto que apresenta um caráter crítico, pois só a letra tem o poder de conscientizar. Contudo, o estudo da melodia e da interpretação permite um maior entendimento do texto e de possíveis deslocamentos de significado por meio da enfatização de algumas palavras que mudam sua acentuação na melodia e na interpretação, mediante os destaques que a intérprete realiza quando utiliza os parâmetros não sintáticos supracitados.

\section{REFERÊNCIAS}

ANDRADE, Oswald de. Santeiro do mangue e outros poemas. São Paulo: Globo: Secretaria de Estado de Cultura, 1991.

BACHELARD, Gaston. A poética do espaço. In: Os Pensadores. São Paulo: Abril Cultural, 1978.

CANDIDO, Antonio. Estudo analítico do poema. São Paulo: EDUSP/ FFLCH, USP, 1996.

CAVARERO, Adriana. Vozes plurais: filosofia da expressão vocal. Belo Horizonte: UFMG, 2011.

ECO, Umberto. Interpretação e Superinterpretação. São Paulo: Martins Fontes, 2005.

Os limites da interpretação. São Paulo: Perspectiva, 2010.

GAYOTTO, Lucia Helena. Voz partitura da ação. São Paulo: Summus, 1997. 
GOUVEIA, Sylvia Cristina Toledo. Maria Bethânia, Corpo e Voz em Cena: a performance de Carcará. Dissertação (Mestrado em Literatura) Florianópolis. Universidade Federal de Santa Catarina, 2012.

NASCIMENTO, Elilson Gomes do. Flores horizontais: uma parceria atemporal entre Oswald e Wisnik. Revista Brasileira de Estudos da Canção, n. 2, julho-dezembro, 2012.

RICOUER, Paul. A memória, a história, o esquecimento. Campinas: Unicamp, 2007.

SARATH, Edward. Music theory through improvisation. New York and London: Routledge, 2010. Arquivo Kindle.

TINOCO, Robson Coelho; DE ALEXANDRIA, Marília. Linguagem de tradição e rupturas construtivas: Uma versão melopoética. Revista da Anpoll, v. 1, n. 23, 2007.

Poemas, música e contemporaneidade: imagens de uma dialogia melopoética. Revista Lumen et Virtus. v. I, n. 2, p. 208-217, 2010. Disponível em: <http://www.jackbran.com.br/lumen_et_virtus/ numero2/.../robsontinoco.pdf> Acesso em: 15 ago. 2014.

ZUMTHOR, Paul. Introdução à poesia oral. São Paulo: Hucitec, 1997.

Recebido em: 14 abr. 2018

Aceito em: 22 jun. 2018 